\title{
0291 INCIDENCE AND MORTALITY OF BURN INJURIES IN SULAYMANIYAH, IRAO
}

N Othman*, D Kendrick Correspondence: College of Medicine, University of Sulaimani, Sulaymaniyah, NA, Iraq

10.1136/ip.2010.029215.291

Background Little is known about burns in Iraq. This study was undertaken to investigate epidemiology of burn injuries in Sulaymaniyah province with 1.7 million people.

Methods A prospective study from November 2007 to November 2008 involving all patients attending for a new burn injury.

Results 2975 patients were recruited (male 52\%, female 48\%; median age 18years). All-age incidence of burns was 389/100 000 person-years (pys) and 1044/100 000 pys in preschool children. The mechanisms of injury included scalds (53\%), flame (37\%), contact $(7 \%)$, chemical (1\%), electrical $(1 \%)$ and explosives $(1 \%)$. Most burns occurred at home $(83 \%$; male $68 \%$, female $96 \%)$. There were 884 admissions (43/100 000 pys) with a significantly higher admission rate in females (males 37 , females 49) and the highest rate in preschool children (95/100 000 pys). Flame injuries accounted for most women admissions (91\%) and scalds for most child admissions (84\%). Overall mortality was $8 / 100000$ pys (males 2 , females 14). Median total body surface area (TBSA) burnt was $18 \%$ and median hospital stay was 8 days. In-hospital mortality was $28 \%$. Adjusted ORs for death were 36.4 (95\% CI 15.9 to 83.3 ) for TBSA burnt $\geq 40 \%$; 5.4 (95\% CI 1.7 to 18.5$)$ for age of 60 and over; 3.6 (95\% CI 1.7 to 7.3$)$ for inhalation injury; 5.6 (95\% CI 2.5 to 12.9$)$ for selfinflicted burns and 3.0 (95\% CI 1.3 to 6.8) for autumn season.

Conclusion Burns are an important public health problem in Sulaymaniyah with higher morbidity in children and mortality in women. Preventive interventions are needed focusing on childhood scalds and flame injuries in women. 